\title{
Anion-dependent Catalytic C-C Bond Cleavage of a Lignin Model within a Cationic Metal-organic Framework
}

Walace D. do Pim, ${ }^{\dagger}$ Fernanda G. Mendonça, ${ }^{\dagger}$ Gabriel Brunet, ${ }^{\dagger}$ Glenn A. Facey, ${ }^{\dagger}$ Floris Chevallier, ${ }^{\ddagger}$ Christophe Bucher, $\neq$ R. Tom Baker, ${ }^{*}+$ and Muralee Murugesu ${ }^{*}, \dagger$

'Department of Chemistry and Biomolecular Sciences and Centre for Catalysis Research and Innovation, University of Ottawa, Ottawa, Ontario K1N 6N5, Canada ¥ Laboratoire de Chimie, Univ Lyon, ENS de Lyon, CNRS UMR 5182, Université Claude Bernard Lyon 1, Lyon, France

*To contact the corresponding authors email: M.Murugesu@uottawa.ca and rbaker@uottawa.ca

\section{Table of Contents}

1. General considerations

2. Syntheses

Syntheses of $\left[\mathrm{H}_{4} \mathrm{~L}\right] \mathrm{Cl}_{2}, \quad\left[\mathrm{Cu}_{2}(\mathrm{~L})\left(\mathrm{H}_{2} \mathrm{O}\right)_{2}\right]\left(\mathrm{NO}_{3}\right)_{2} \cdot 5.5 \mathrm{H}_{2} \mathrm{O} \quad(\mathbf{1})$, and 1,2-diphenyl-2methoxyethanol (DPME).

\section{Anion-exchange study}

Procedures for anion-exchange, FT-IR spectra of the anion-exchanged MOFs (Figures S1-S7), sample preparation for ${ }^{15} \mathrm{~N}$ MAS NMR, cages in 1 (Figure S8), SEM and EDS for $\mathrm{Cl}$ and $\mathrm{Cu}$ in $\mathrm{ClO}_{4}{ }^{-} @ 1$ (Figure S9), TGA curves for the anion-exchanged MOFs (Figure S10), PXRD of selected MOFs after exchange of DMF with $\mathrm{CHCl}_{3}$ and air drying (Figure S11) and nitrogen adsorption-desorption of $\mathrm{Cr}_{2} \mathrm{O}_{7}{ }^{2-} @ \mathbf{1}$ and $\mathrm{SCN}^{-} @ 1$ (Figure S12).

4. Aerobic oxidation of lignin model.

Aerobic oxidation of DPME using (i) $\mathbf{1}$ in toluene and pyridine $\left({ }^{1} \mathrm{H}\right.$ NMR spectra are shown in Figure S13), (ii) $\mathbf{1}$ and anion-exchanged MOFs in toluene ( ${ }^{1} \mathrm{H}$ NMR data are shown in Figures S14, S15, and S17; GC-MS chromatograms are shown in Figure S16), (iii) 1 in the presence of different concentrations of $\mathrm{ClO}_{4}^{-}$, (iv) $\left(n-\mathrm{Bu}_{4} \mathrm{~N}\right) \mathrm{ClO}_{4}\left({ }^{1} \mathrm{H} \mathrm{NMR}\right.$ data are shown in Figure S18). Volumes of anions used in this study (Tables S1 and S2).

5. Characterization of $\mathrm{ClO}_{4}^{-} @ 1$ after catalysis S-19 
FT-IR (Figure S19) and PRXD (Figure S20).

6. Reuse of $\mathrm{ClO}_{4}^{-} @ 1$

${ }^{1} \mathrm{H}$ NMR spectra are shown in Figure S21.

7. Reuse of the solution after aerobic oxidation of DPME using $\mathrm{ClO}_{4}^{-} @ 1$ S-21

${ }^{1} \mathrm{H}$ NMR spectra are shown in Figure S22.

8. Aerobic oxidation of DPME using $\mathrm{ClO}_{4}{ }^{-}$@ 1 in the presence of TEMPO $(2,2,6,6-$ tetramethylpiperidine-1-oxyl) or 4-acetamido-TEMPO .................... S-22

9. Aerobic oxidation of DPME using NOTT-102 ................................ S-23

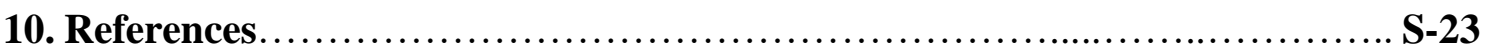

\section{General considerations}

All manipulations were performed under aerobic conditions using materials as received from commercial suppliers (Alfa Aesar, TCI, and Sigma Aldrich). Synthesis of MOF NOTT-102 was performed as described previously. ${ }^{1}$ Deuterated chloroform $\left(\mathrm{CDCl}_{3}\right)$ was purchased from Cambridge Isotope Laboratories. FT-IR spectra were recorded on a Nicolet 6700 FT-IR spectrometer equipped with an attenuated total reflectance accessory (ATR), in the 4000-600 $\mathrm{cm}^{-1}$ range. Powder X-ray diffraction (PXRD) measurements for bulk samples were carried out using a Rigaku Ultima IV X-ray powder diffractometer. The Parallel Beam mode was employed to collect the data using $\mathrm{Cu}-\mathrm{K} \alpha$ radiation $(\lambda=$ $1.541836 \AA$ ) in a $2 \theta$ range of $4-20^{\circ}$ at room temperature. ${ }^{15} \mathrm{~N}$ MAS NMR spectra were recorded at room temperature on a Bruker AVANCE III $400 \mathrm{MHz}$ solid-state NMR spectrometer using $4 \mathrm{~mm}$ zirconia rotors. High power ${ }^{1} \mathrm{H}$ decoupling was employed with a sample spinning speed of $10 \mathrm{kHz}$. The spectra were collected with 1024 scans using $90^{\circ}$ pulses $(7.5 \mu \mathrm{sec})$ and a 15 second recycle time. The chemical shifts were measured with respect to solid ${ }^{15} \mathrm{NH}_{4} \mathrm{Cl}$ at $0 \mathrm{ppm}$. Thermogravimetric analyses (TGA) were performed on a TA Instruments Q5000 TGA analyzer from room temperature to $800{ }^{\circ} \mathrm{C}$ 
in a nitrogen atmosphere, with a heating rate of $5^{\circ} \mathrm{C} \min ^{-1}$. Scanning electron microscopy (SEM) images were collected on a JEOL JSM-7500F field emission scanning electron microscope. ${ }^{1} \mathrm{H}$ NMR spectra were recorded at room temperature on a Bruker AVANCE II $400 \mathrm{MHz}$ spectrometer, with chemical shifts $(\delta)$ referenced to the residual solvent signal. GC-MS analyses were performed on an Agilent Technologies 6890N GC system equipped with an Agilent Technologies 5973Network mass selective detector.

\section{Syntheses}

$\left[\mathbf{H}_{4} \mathbf{L}\right] \mathbf{C l}_{2}$. The synthesis of the ligand $\left[\mathrm{H}_{4} \mathrm{~L}\right] \mathrm{Cl}_{2}$ was conducted in two steps according to the Zincke reaction. In the first step, the Zincke salt 4,4'-bipyridinium-1,1'bis-(2,4dinitrophenyl) dichloride was obtained as follows: $1.562 \mathrm{~g}$ (10 mmol) of 4,4'-bipyridine and $4.051 \mathrm{~g}(20 \mathrm{mmol})$ of 1-chloro-2,4-dinitrobenzene were suspended in $25 \mathrm{~mL}$ of ethanol (99\%). The mixture was heated under reflux for $48 \mathrm{~h}$. After this period, the precipitate was filtered off and was washed with ethanol (99\%), acetone, and diethyl ether (yield $4.260 \mathrm{~g}, 76 \%$ ). In the second step, $2.806 \mathrm{~g}$ (5 mmol) of Zincke salt and $2.174 \mathrm{~g}$ (12 mmol) of 5-aminoisophthalic acid were suspended in $25 \mathrm{~mL}$ of ethanol (99\%) in a $50 \mathrm{~mL}$ round bottom flask. The mixture was heated under reflux for $48 \mathrm{~h}$. After the reaction, the solid was filtered off, washed with ethanol (99\%), acetone and diethyl ether and dried to yield $2.229 \mathrm{~g}(80 \%) .{ }^{1} \mathrm{H}$ NMR (400 MHz, DMSO-d 6$): \delta 8.21(\mathrm{~d}, 2 \mathrm{H}), 8.84(\mathrm{~m}, 6 \mathrm{H}), 9.31$ $(\mathrm{d}, 2 \mathrm{H}), 9.38(\mathrm{~d}, 4 \mathrm{H})$.

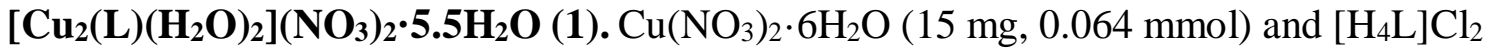
(5 mg, $0.009 \mathrm{mmol}$ ) were dissolved in $1.00 \mathrm{~mL}$ of $\mathrm{DMF}$, and then $1.05 \mathrm{~mL}$ of $\mathrm{HNO}_{3}(2.7$ mol $\mathrm{L}^{-1}$ in DMF) was added. The solution was sealed in a $20 \mathrm{~mL}$ vial and heated at $80^{\circ} \mathrm{C}$ for $48 \mathrm{~h}$, then cooled to room temperature. Green block crystals of the MOF were 
obtained, rinsed with DMF several times, separated by filtration, and dried in air. Yield: 93 wt.\% based on the ligand.

1,2-diphenyl-2-methoxyethanol (DPME). Benzoin methyl ether (1.005 g, 4.4 mmol) was dissolved in $35 \mathrm{~mL}$ of dry methanol. The mixture was treated with small portions of $\mathrm{NaBH}_{4}(0.169 \mathrm{~g}, 4.4 \mathrm{mmol})$ cooling with a cold-water bath and then stirred for $1 \mathrm{~h}$. A saturated solution of $\mathrm{NH}_{4} \mathrm{Cl}(5 \mathrm{~mL})$ followed by $10 \mathrm{~mL}$ of $\mathrm{DCM}$ was then added. The organic layer was extracted, washed with water, dried with $\mathrm{MgSO}_{4}$ and concentrated on a rotatory evaporator to give a white powder. The crude solid was recrystallized from hot methanol. Yield $0.711 \mathrm{~g}(70 \%)$. Integration of the benzylic protons in ${ }^{1} \mathrm{H}$ NMR spectrum showed that the product was a mixture of 90:10 erythro $(\mathrm{R}, \mathrm{S}+\mathrm{S}, \mathrm{R})$ : threo $(\mathrm{R}, \mathrm{R}+\mathrm{S}, \mathrm{S})$ diastereomers, as previously reported. ${ }^{2}{ }^{1} \mathrm{H} \mathrm{NMR}\left(400 \mathrm{MHz}, \mathrm{CDCl}_{3}\right.$ ): $\delta$ 7.31-7.22 (ov m, 7H, Ar), 7.22-7.11 (ov m, 3H, Ar), 4.90 (d, 1H, J = 5.5 Hz, CH erythro isomer), 4.65 (d, $1 \mathrm{H}, \mathrm{J}=8.7 \mathrm{~Hz}, \mathrm{CH}$ threo isomer), $4.35(\mathrm{~d}, 1 \mathrm{H}, \mathrm{J}=5.5 \mathrm{~Hz}, \mathrm{CH}$ erythro isomer), 4.12 (d, $1 \mathrm{H}, \mathrm{J}=8.2 \mathrm{~Hz}, \mathrm{CH}$ threo isomer), 3.31 (s, 3H, $\mathrm{OCH}_{3}$, erythro isomer), 3.24 (s, $3 \mathrm{H}, \mathrm{OCH}_{3}$, threo isomer).

\section{Anion-exchange study}

\subsection{Procedures for anion-exchange}

$\mathbf{C l O}_{4}^{-} @ \mathbf{1} .30 \mathrm{mg}$ of $\mathbf{1}$ was immersed in $10 \mathrm{~mL}$ of a $1 \mathrm{~mol} \mathrm{~L}{ }^{-1}$ DMF solution of $(n-$

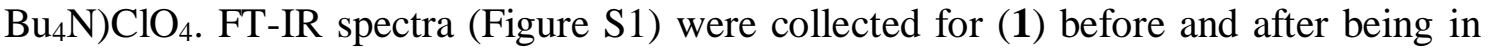
direct contact for 1,4 and $24 \mathrm{~h}$ with $\left(n-\mathrm{Bu}_{4} \mathrm{~N}\right) \mathrm{ClO}_{4}$ solution at room temperature.

$\mathbf{B F}_{4}^{-} @ 1$ 1. $30 \mathrm{mg}$ of $\mathbf{1}$ was immersed in $10 \mathrm{~mL}$ of a $1 \mathrm{~mol} \mathrm{~L}^{-1} \mathrm{DMF}$ solution of $(n$ $\mathrm{Bu}_{4} \mathrm{~N}$ )BF $\mathrm{BF}_{4}$ FT-IR spectra (Figure $\mathrm{S} 2$ ) were collected for (1) before and after being in direct contact for 1,4 and $24 \mathrm{~h}$ with $\left(n-\mathrm{Bu}_{4} \mathrm{~N}\right) \mathrm{BF}_{4}$ solution at room temperature. 
$\mathbf{S C N}^{-} @ \mathbf{1} .30 \mathrm{mg}$ of $\mathbf{1}$ was immersed in $10 \mathrm{~mL}$ of a $1 \mathrm{~mol} \mathrm{~L}{ }^{-1}$ DMF solution of $(n-$ $\mathrm{Bu}_{4} \mathrm{~N}$ )SCN. FT-IR spectra (Figure S3) were collected for (1) before and after being in direct contact for $12,24,36$ and $48 \mathrm{~h}$ with $\left(n-\mathrm{Bu}_{4} \mathrm{~N}\right) \mathrm{SCN}$ solution at room temperature.

BPh $_{4}^{-} @ 1.30$ mg of 1 was immersed in $10 \mathrm{~mL}$ of a $1 \mathrm{~mol} \mathrm{~L}^{-1} \mathrm{DMF}$ solution of $\mathrm{Na}\left(\mathrm{BPh}_{4}\right)$. FT-IR spectra (Figure S4) were collected for (1) before and after being in direct contact for 1, 4 and 24 hours with $\mathrm{Na}\left(\mathrm{BPh}_{4}\right)$ solution at room temperature.

$\mathbf{N}(\mathbf{C N})_{2}{ }^{-} @ \mathbf{1} .30 \mathrm{mg}$ of $\mathbf{1}$ was immersed in $10 \mathrm{~mL}$ of a dilute $(50 \mathrm{ppm}) \mathrm{DMF}$ solution of $\mathrm{Na}\left[\mathrm{N}(\mathrm{CN})_{2}\right]$. FT-IR spectra (Figure S5) were collected for (1) before and after being in direct contact for $1,24,48$, and $72 \mathrm{~h}$ with $\mathrm{Na}\left[\mathrm{N}(\mathrm{CN})_{2}\right]$ solution at room temperature.

$\mathrm{Cr}_{2} \mathbf{O}_{7}{ }^{2-} @ \mathbf{1} .30 \mathrm{mg}$ of $\mathbf{1}$ was immersed in $10 \mathrm{~mL}$ of a dilute (50 ppm) DMF solution of $\mathrm{K}_{2} \mathrm{Cr}_{2} \mathrm{O}_{7}$. FT-IR spectra (Figure S6) were collected for (1) before and after being in direct contact for 1, 3, 24 and $48 \mathrm{~h}$ with $\mathrm{K}_{2} \mathrm{Cr}_{2} \mathrm{O}_{7}$ solution at room temperature.

$\mathbf{S}_{\mathbf{2}} \mathbf{O}_{4}{ }^{2-} @ \mathbf{1} .30 \mathrm{mg}$ of $\mathrm{NO}_{3}{ }^{-} @ \mathbf{1}$ was immersed in $10 \mathrm{~mL}$ of a dilute (50 ppm) DMF solution of $\mathrm{Na}_{2} \mathrm{~S}_{2} \mathrm{O}_{4}$. FT-IR spectra (Figure S7) were collected for (1) before and after being in direct contact for $1,24,48$ and $72 \mathrm{~h}$ with $\mathrm{Na}_{2} \mathrm{~S}_{2} \mathrm{O}_{4}$ solution at room temperature.

\section{Observations}

During the anion exchange FT-IR monitoring, a few crystals of the MOF were collected from the exchanging solutions and washed abundantly with a DMF solution followed by residual solvent removal using a filter paper before recording infrared spectra. 


\subsection{FT-IR spectra of anion-exchanged MOFs}

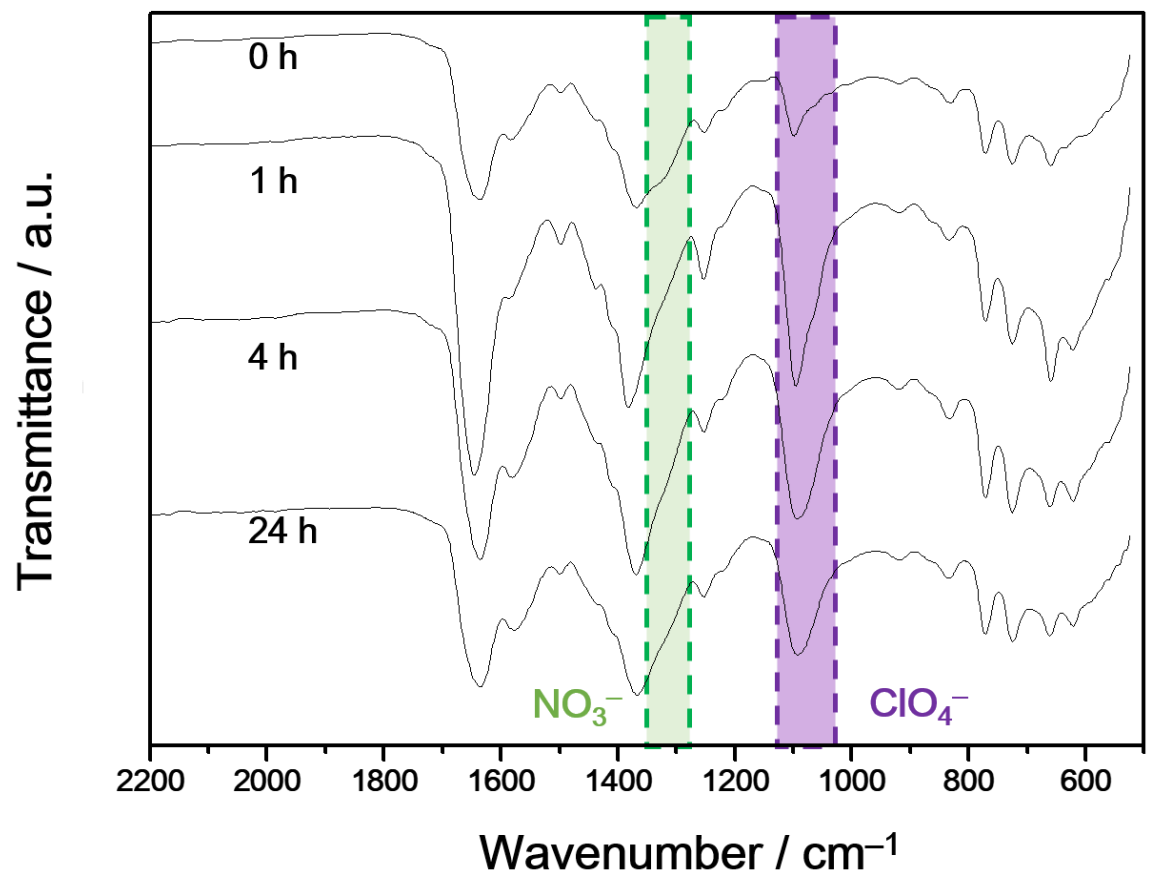

Figure S1. Infrared spectra of $\mathrm{NO}_{3}{ }^{-} @ 1$ recorded over $24 \mathrm{~h}$, soaked in a DMF solution of tetrabutylammonium perchlorate displaying the vanishing of $\mathrm{NO}_{3}{ }^{-}$and the emergence of a $\mathrm{ClO}_{4}^{-}$band.

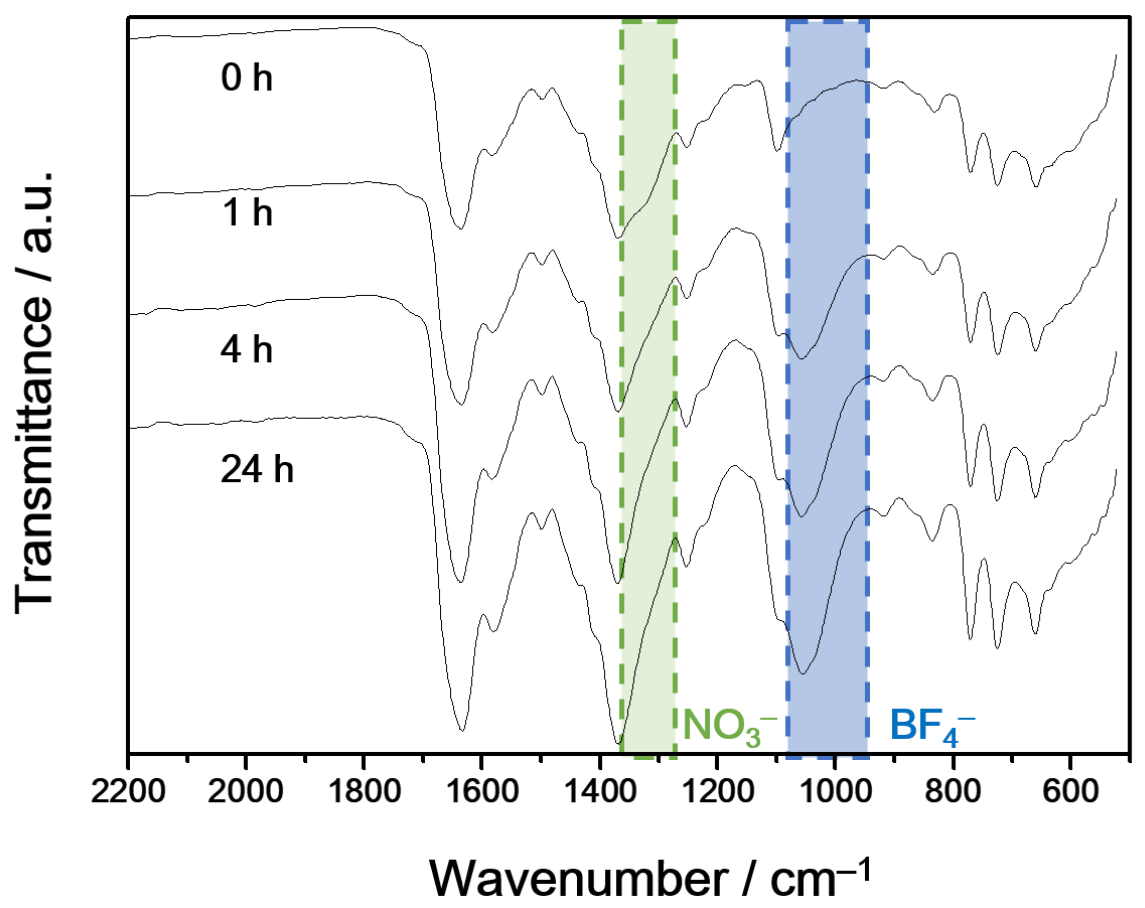

Figure S2. Infrared spectra of $\mathrm{NO}_{3}{ }^{-} @ 1$ recorded over $24 \mathrm{~h}$, soaked in a DMF solution of tetrabutylammonium tetrafluoroborate displaying the vanishing of $\mathrm{NO}_{3}{ }^{-}$and the emergence of a $\mathrm{BF}_{4}^{-}$band. 


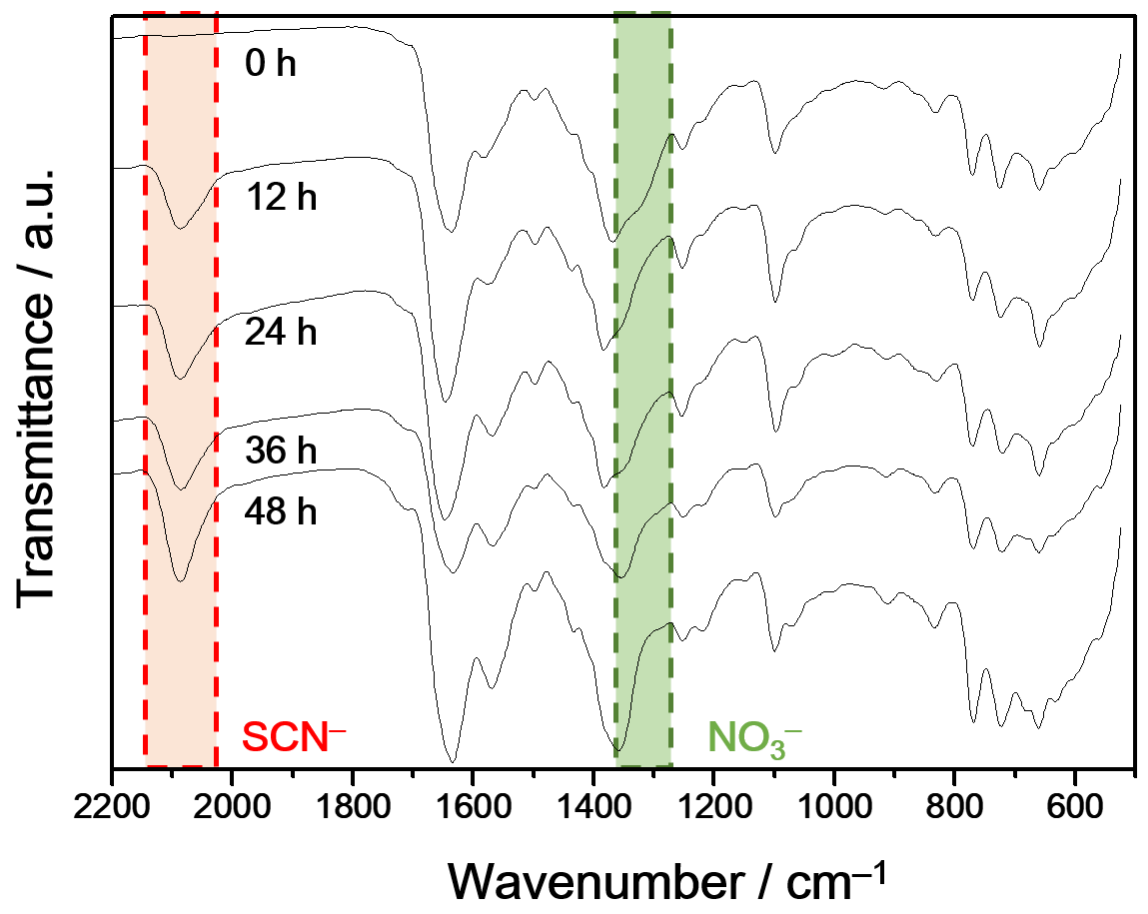

Figure S3. Infrared spectra of $\mathrm{NO}_{3}{ }^{-} @ 1$ recorded over $48 \mathrm{~h}$, soaked in a DMF solution of tetrabutylammonium thiocyanate displaying the vanishing of $\mathrm{NO}_{3}{ }^{-}$and the emergence of a $\mathrm{SCN}^{-}$band.

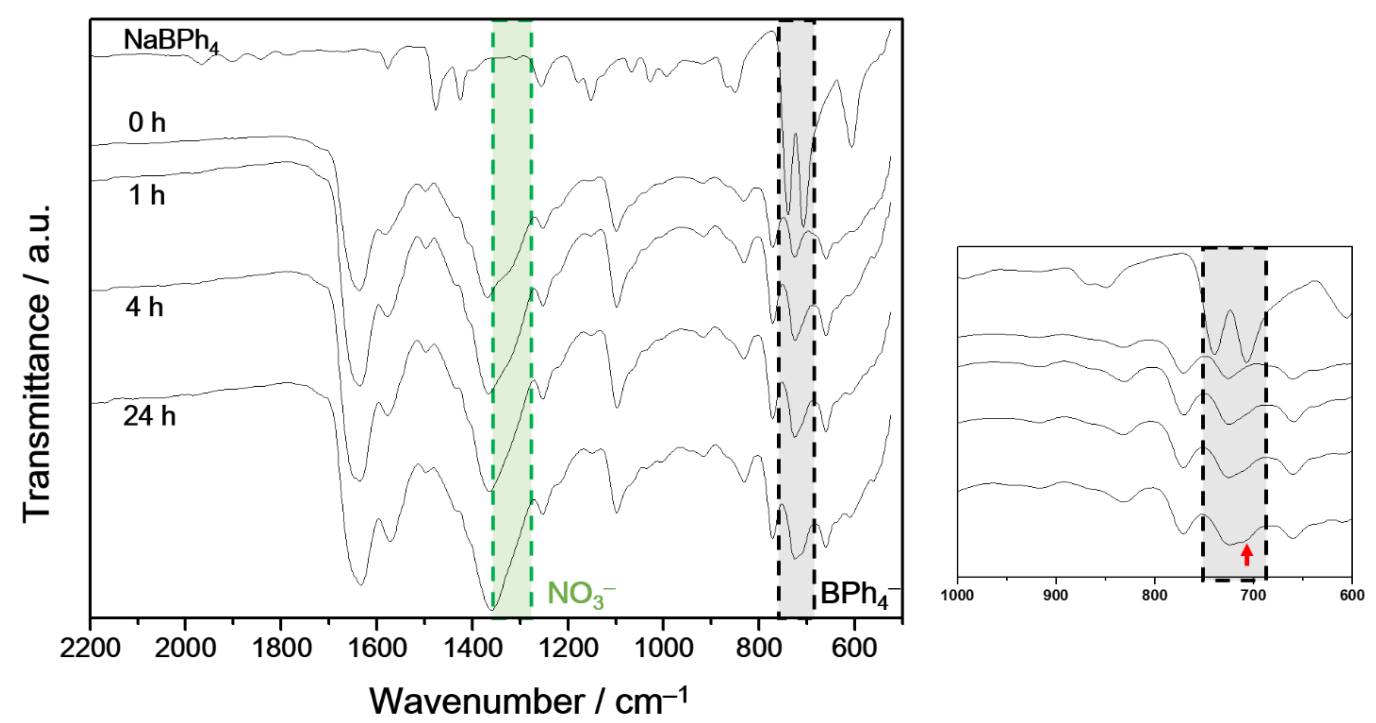

Figure S4. Infrared spectra of $\mathrm{NO}_{3}{ }^{-} @ 1$ recorded over $24 \mathrm{~h}$, soaked in a DMF solution of sodium tetraphenylborate displaying the vanishing of $\mathrm{NO}_{3}{ }^{-}$and the emergence of a $\mathrm{BPh}_{4}{ }^{-}$ shoulder, shown in detail in the spectrum on right by the red arrow. 


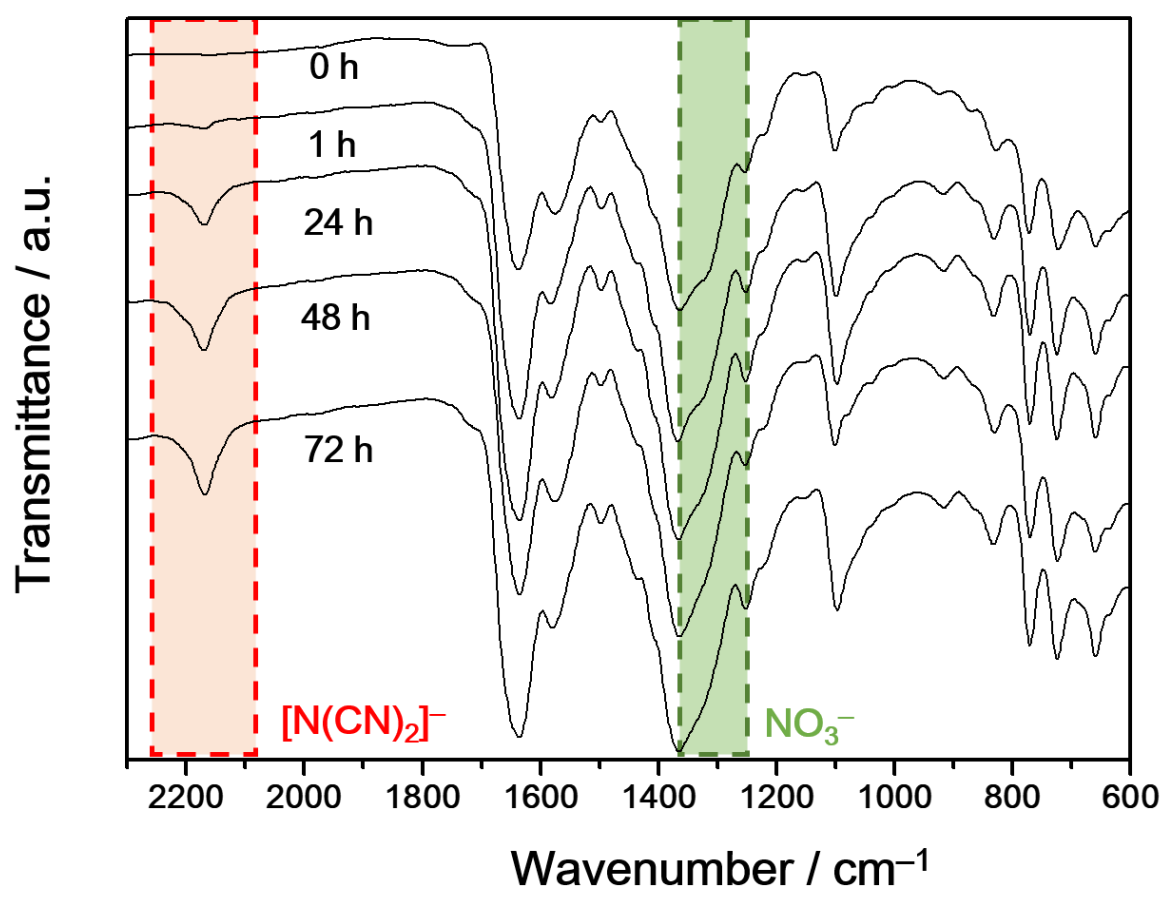

Figure S5. Infrared spectra of $\mathrm{NO}_{3}{ }^{-} @ 1$ recorded over $72 \mathrm{~h}$, soaked in a dilute DMF solution $(50 \mathrm{ppm})$ of sodium dicyanamide displaying the vanishing of $\mathrm{NO}_{3}{ }^{-}$and the emergence of a $\mathrm{N}(\mathrm{CN})_{2}{ }^{-}$band.

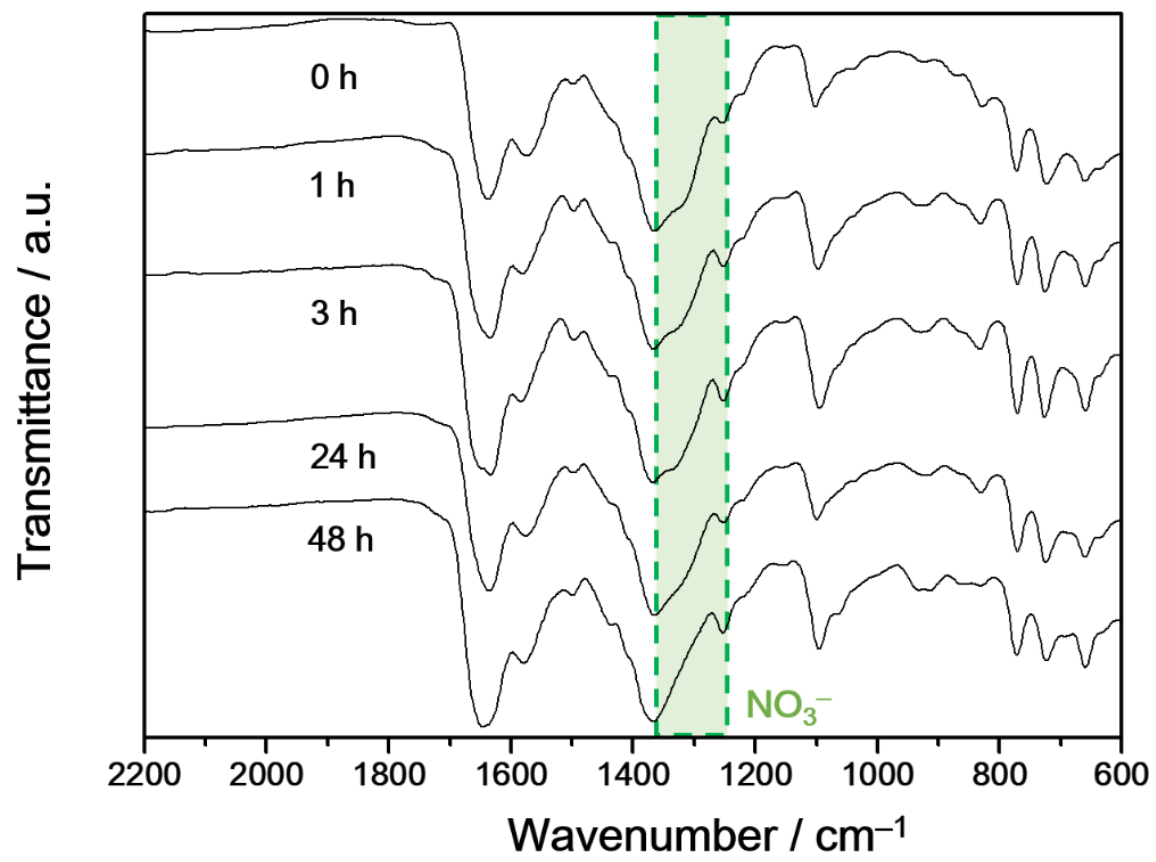

Figure S6. Infrared spectra of $\mathrm{NO}_{3}{ }^{-} @ 1$ recorded over $48 \mathrm{~h}$, soaked in a dilute DMF solution $(50 \mathrm{ppm})$ of potassium dichromate displaying the vanishing of $\mathrm{NO}_{3}{ }^{-}$. 


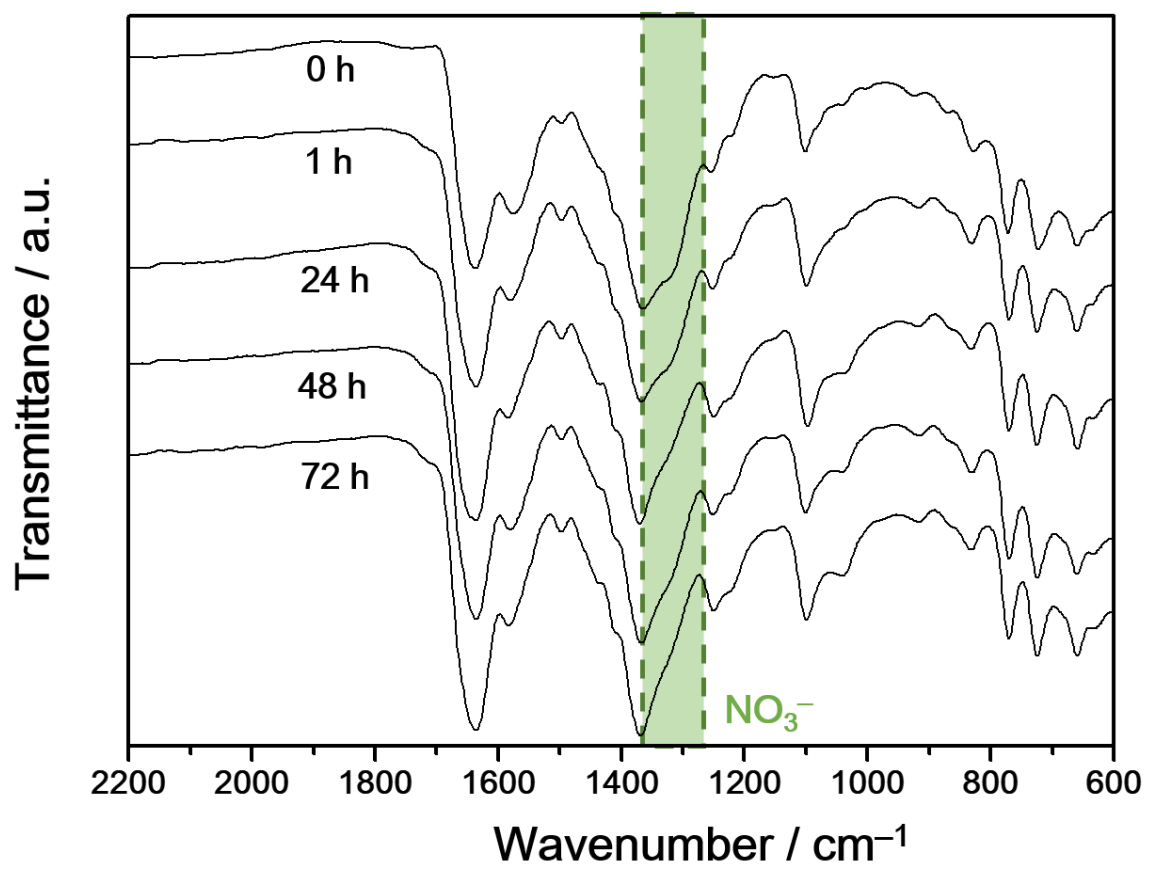

Figure S7. Infrared spectra of $\mathrm{NO}_{3}{ }^{-} @ 1$ recorded over $72 \mathrm{~h}$, soaked in a dilute DMF solution $(50 \mathrm{ppm})$ of sodium dithionite displaying the vanishing of $\mathrm{NO}_{3}{ }^{-}$.

\subsection{Sample preparation for ${ }^{15} \mathrm{~N}$ MAS NMR}

$150 \mathrm{mg}$ of the as-synthesized $\mathrm{NO}_{3}{ }^{-} @ \mathbf{1}$ was immersed in $5.0 \mathrm{~mL}$ of a $0.25 \mathrm{~mol} \mathrm{~L}^{-1} \mathrm{DMF}$ solution of $\mathrm{NH}_{4}{ }^{15} \mathrm{NO}_{3}$ being the solution renewed twice and maintained in contact with the crystals for $24 \mathrm{~h}$ each, totalizing $72 \mathrm{~h}$. The solid was separated, dried under air and the ${ }^{15} \mathrm{~N}$ MAS NMR spectrum recorded. After analysis, the sample was recovered and immersed in $5.0 \mathrm{~mL}$ of a $1 \mathrm{~mol} \mathrm{~L}{ }^{-1}$ solution of $\left(n-\mathrm{Bu}_{4} \mathrm{~N}\right) \mathrm{ClO}_{4}$ in $\mathrm{DMF}$ being the solution renewed six times and maintained in contact with the crystals for $24 \mathrm{~h}$ each, totalizing $144 \mathrm{~h}$, to ensure maximum exchange of ${ }^{15} \mathrm{NO}_{3}^{-}$with $\mathrm{ClO}_{4}^{-}$anions. The solid was separated, washed several times with fresh DMF, dried under air, and another ${ }^{15} \mathrm{~N}$ MAS NMR spectrum was recorded for the anion-exchanged sample. Both samples were loaded such that they filled $4 \mathrm{~mm}$ MAS rotors and data were collected for each under identical 
conditions using the same number of scans such that a semi-quantitative intensity comparison could be made between the two spectra.

\subsection{Cages in 1}
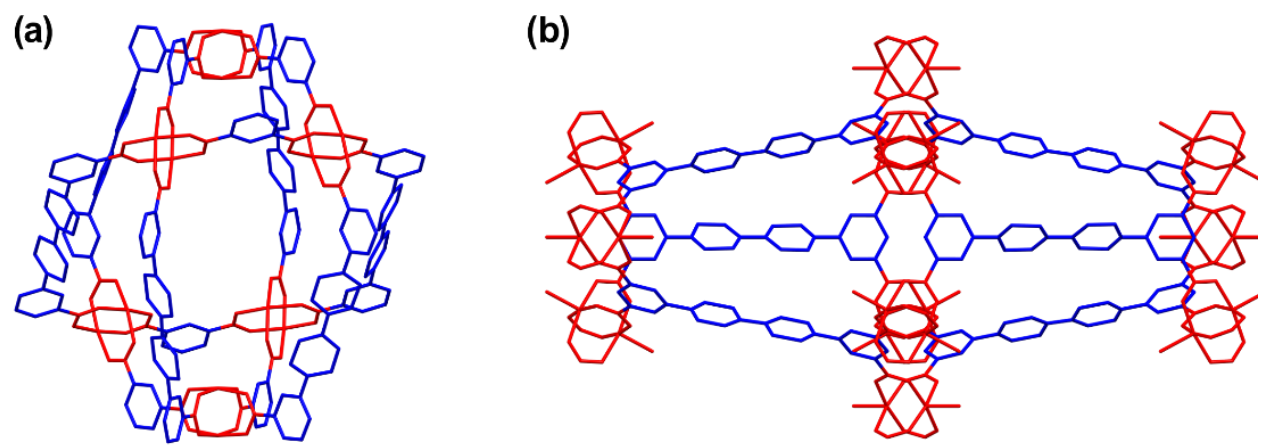

Figure S8. Representation of the two different cages in 1: (a) the spherical cage $\left(\mathrm{Cu}_{12} \mathrm{~L}_{12}\right)$ and (b) the large rod-shaped cage $\left(\mathrm{Cu}_{24} \mathrm{~L}_{6}\right)$.

\subsection{SEM/EDS for $\mathrm{ClO}_{4}^{-} @ 1$}
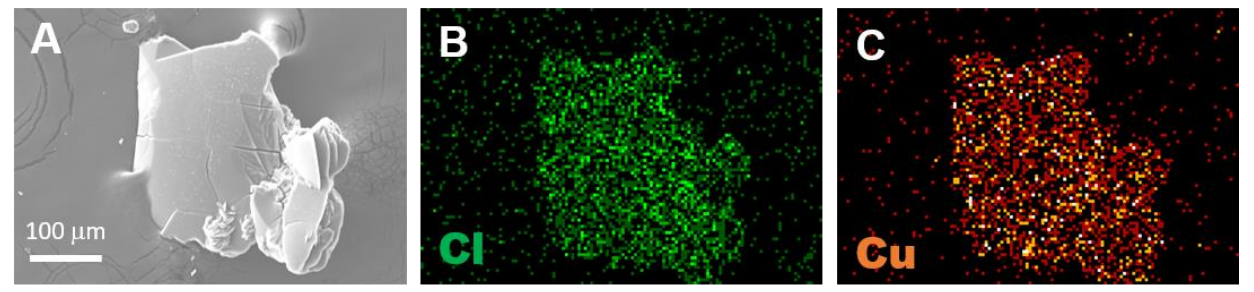

Figure S9. SEM image and EDS mapping for $\mathrm{Cl}$ and $\mathrm{Cu}$ of $\mathrm{ClO}_{4}^{-} @ \mathbf{1}$. 
3.6. TGA of anion-exchanged MOFs

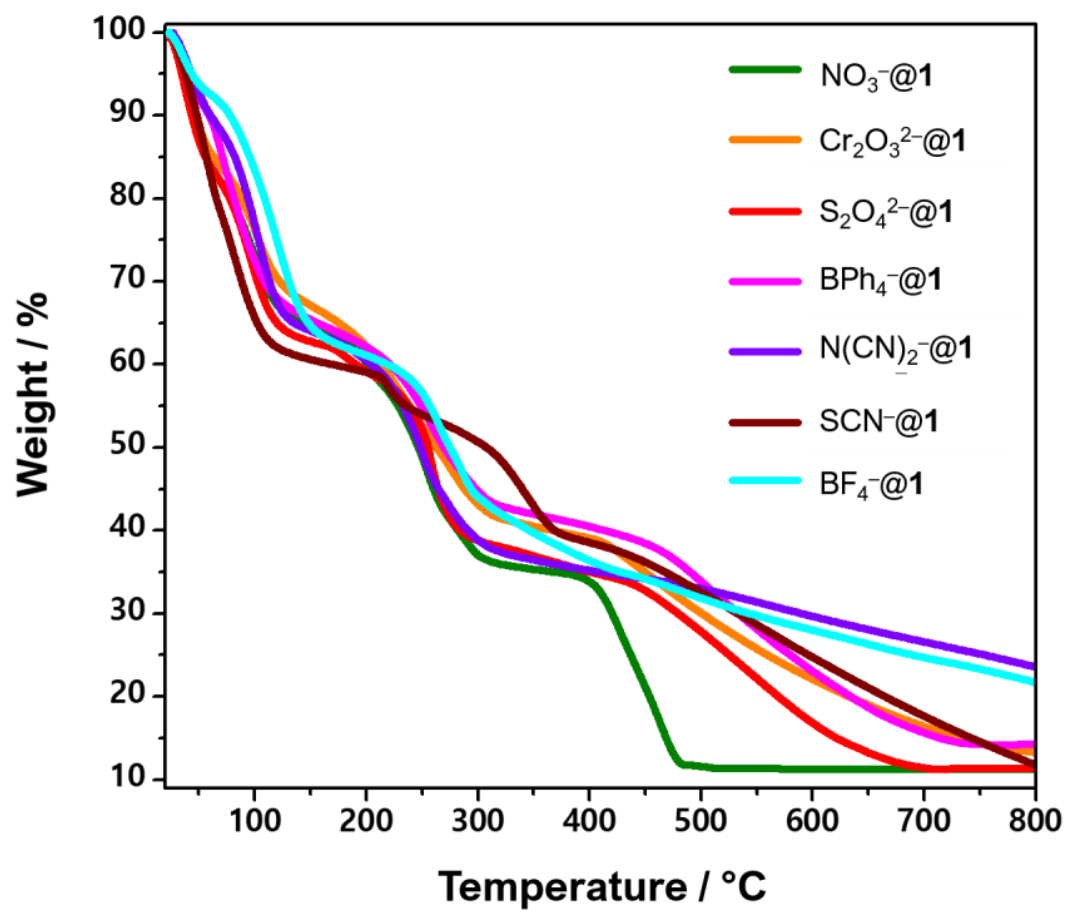

Figure S10. TGA curves of the as-synthesized $\mathrm{NO}_{3}{ }^{-} @ 1$ and its anion-exchanged derivatives under $\mathrm{N}_{2}$ atmosphere. 


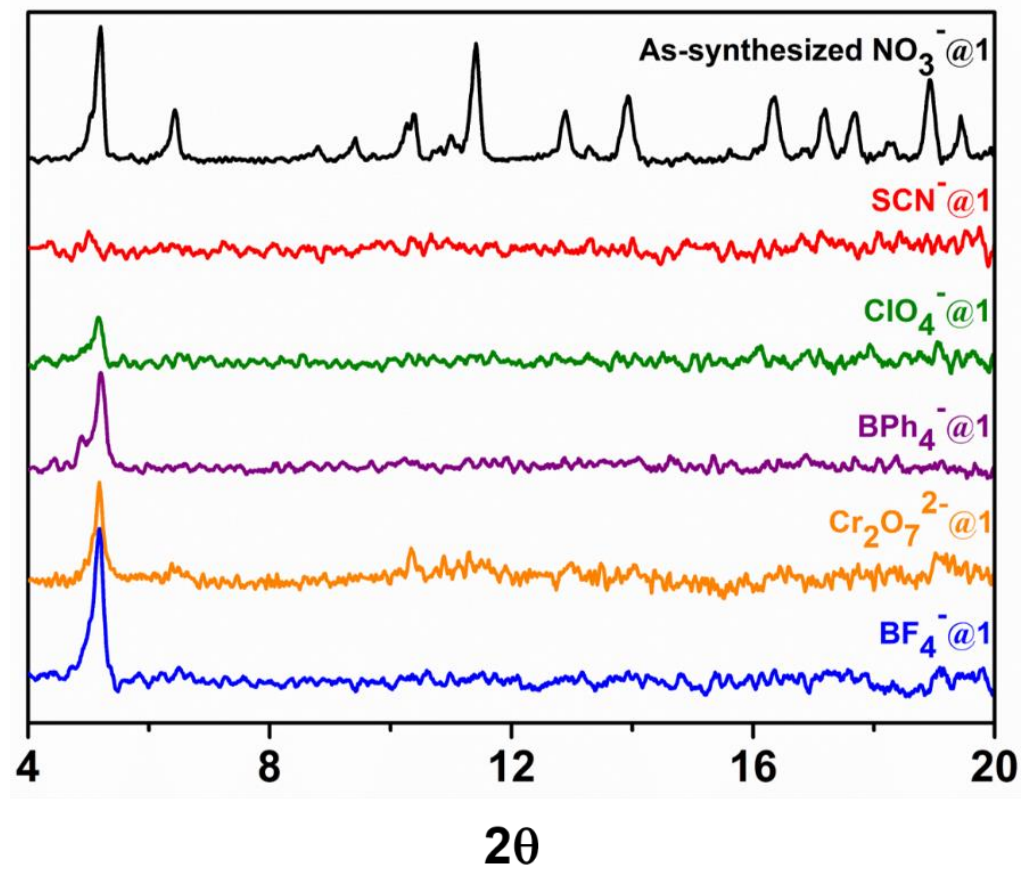

Figure S11. PXRD of as-synthesized 1 and of anion-exchanged $\mathrm{SCN}^{-} @ 1, \mathrm{ClO}_{4}^{-} @ 1$, $\mathrm{BPh}_{4}{ }^{-} @ \mathbf{1}, \mathrm{Cr}_{2} \mathrm{O}_{7}{ }^{2-} @ \mathbf{1}$, and $\mathrm{BF}_{4}^{-} @ \mathbf{1}$ after exchange of DMF with $\mathrm{CHCl}_{3}$ and air drying.

\subsection{Nitrogen adsorption-desorption of $\mathrm{Cr}_{2} \mathrm{O}_{7}{ }^{2-} @ 1$ and $\mathrm{SCN}^{-} @ 1$}

A

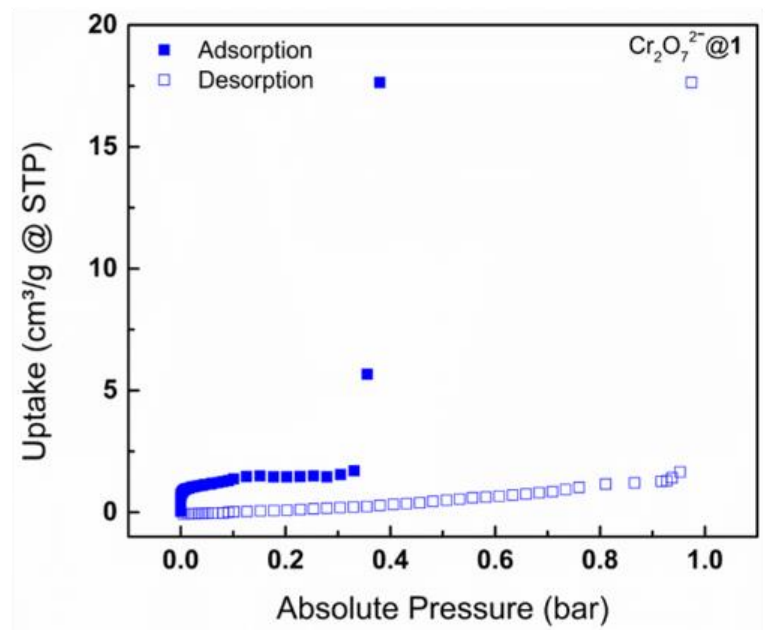

B

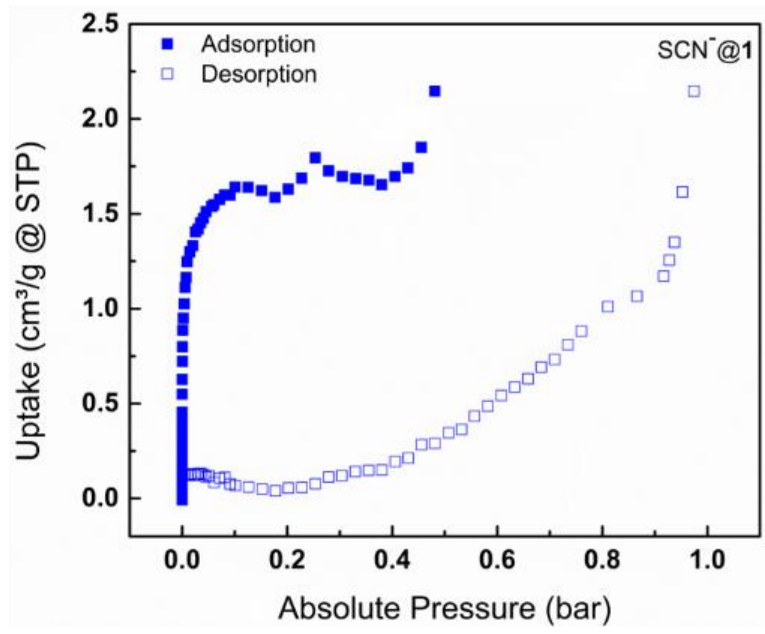

Figure S12. Nitrogen adsorption-desorption of $\mathrm{Cr}_{2} \mathrm{O}_{7}^{2-} @ 1$ (A) and $\mathrm{SCN}^{-} @ 1$ (B) showing the collapse of both structures characterized by the neglected $\mathrm{N}_{2}$ uptakes for MOFs. 


\section{Aerobic oxidation of lignin model}

\subsection{Aerobic oxidation of DPME using 1 in toluene and pyridine}

In $20 \mathrm{~mL}$ glass capped vials, fresh aliquots of the desired solvent (toluene or pyridine, 1 $\mathrm{mL})$ were added to approximately $25 \mathrm{mg}(0.03 \mathrm{mmol})$ of the as-synthesized $\mathrm{NO}_{3}{ }^{-} @ 1$ in order to remove the DMF guests within the pores. The solvents were renewed three times and maintained in contact with the crystals for $6 \mathrm{~h}$ each, totalizing $24 \mathrm{~h}$. The reactions were then performed using $1 \mathrm{~mL}$ of toluene or pyridine. DPME (34 mg, $0.15 \mathrm{mmol}$ ) was added to the mixture and the capped vials were heated at $100{ }^{\circ} \mathrm{C}$ with constant stirring. Aliquots of the reactions were taken after 24 and $48 \mathrm{~h}$, added to $\mathrm{CDCl}_{3}(1 \mathrm{~mL})$, filtered and examined by ${ }^{1} \mathrm{H}$ NMR spectroscopy (Figure S13).

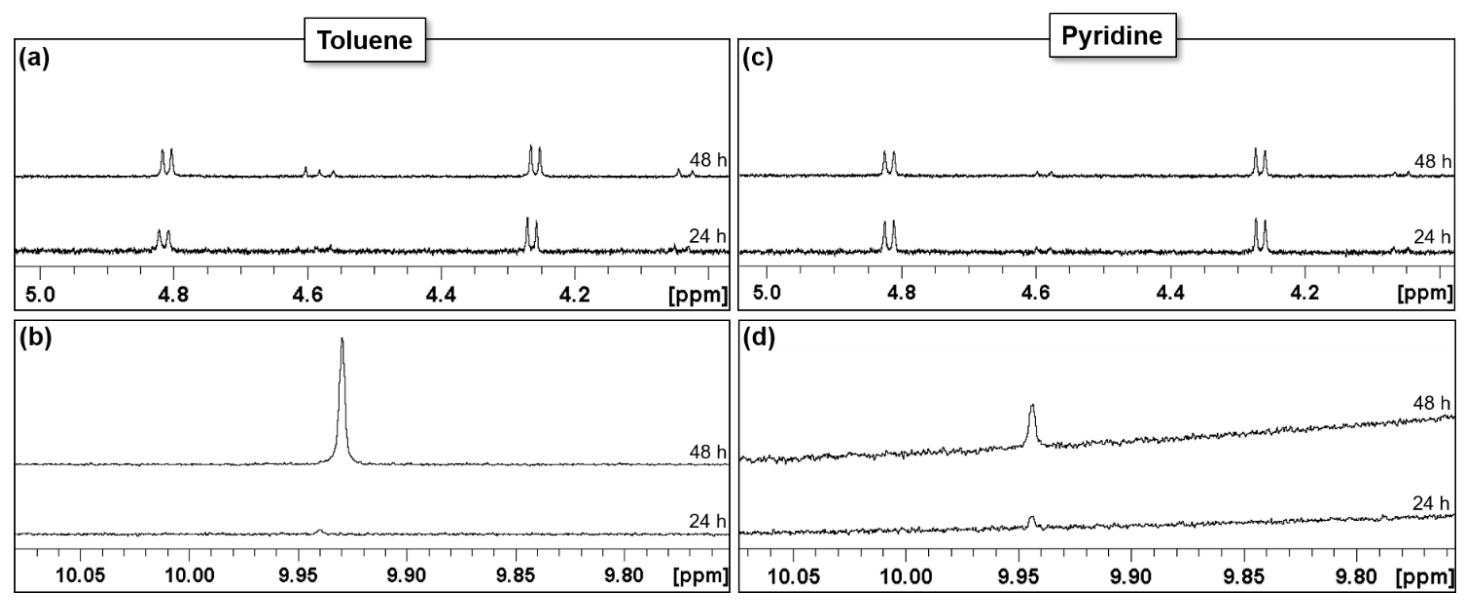

Figure S13. ${ }^{1} \mathrm{H}$ NMR spectra recorded in $\mathrm{CDCl}_{3}$ for the aliquots of reactions performed using MOF 1 in toluene (a,b) and pyridine (c,d) after 24 and 48 h. Spectra (a) and (c) show the peaks related to $\mathrm{CH}$ protons from DPME (region between 4.0 and $5.0 \mathrm{ppm}$ ). Spectra (b) and (d) show the peak related to $\mathrm{CHO}$ proton from product benzaldehyde (region between 9.7 and $10.0 \mathrm{ppm}$ ).

\subsection{Aerobic oxidation of DPME using 1 and anion-exchanged MOFs in toluene}

The reactions were performed as above except that only the aliquots obtained after $48 \mathrm{~h}$ were added to $\mathrm{CDCl}_{3}\left(1 \mathrm{~mL}\right.$ ), filtered and examined by ${ }^{1} \mathrm{H}$ NMR spectroscopy (Figures 
S14, S15, and S17). GC-MS analyses were performed for two selected samples besides the pure substrate, and the chromatograms are presented in Figure S16.

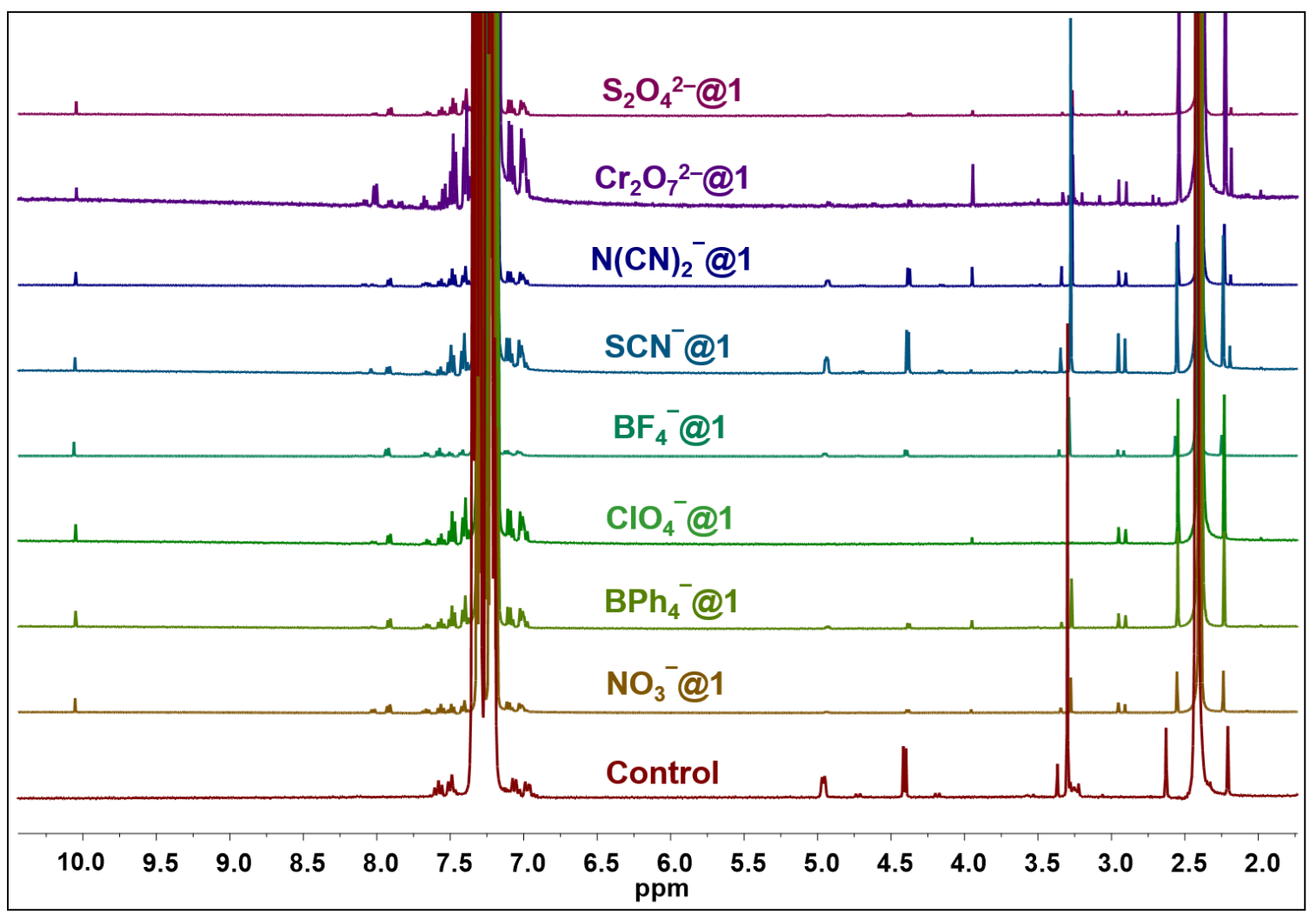

Figure S14. ${ }^{1} \mathrm{H}$ NMR spectra recorded in $\mathrm{CDCl}_{3}$ for the aliquots of reactions performed using MOF 1 and anion-exchanged MOFs in toluene after $48 \mathrm{~h}$. Control experiment: reaction performed without the addition of catalyst. 


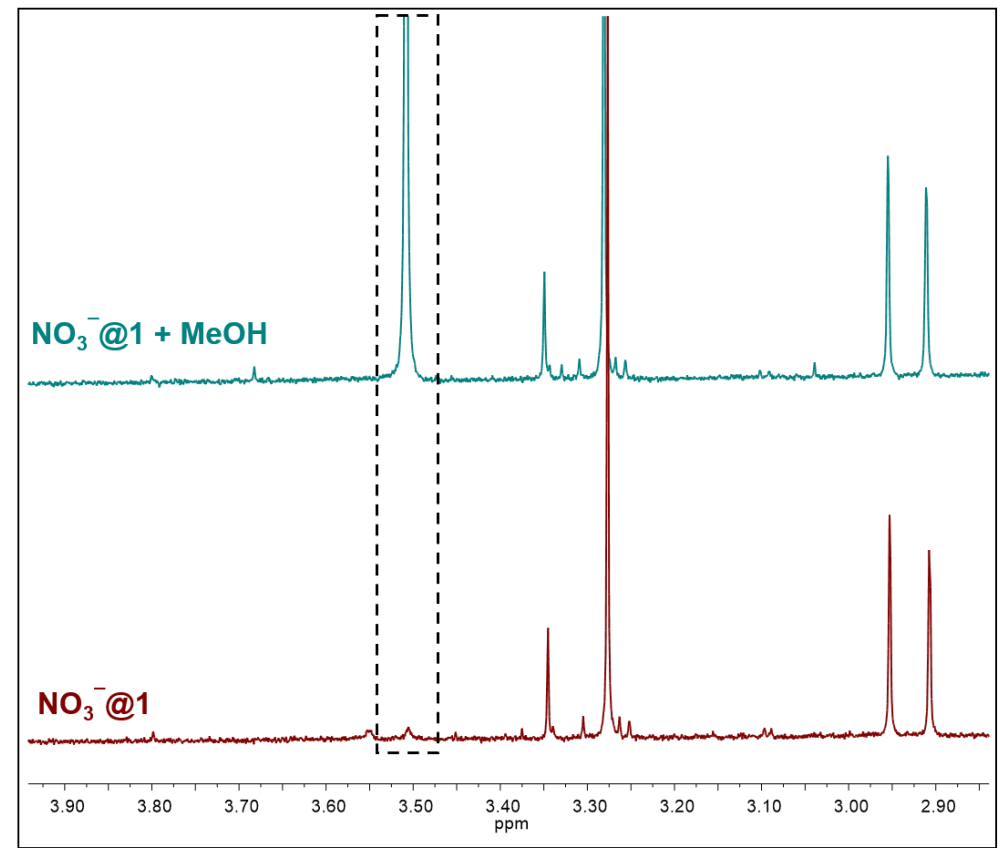

Figure S15. ${ }^{1} \mathrm{H}$ NMR spectra recorded in $\mathrm{CDCl}_{3}$ for the aliquot of reaction performed using MOF 1 before and after addition of one drop of methanol to the NMR tube. The highlighted area shows the spike of one of the pre-existing very low-intense peaks in the spectra at $\delta 3.51 \mathrm{ppm}\left(\mathrm{CH}_{3}\right.$ protons from methanol).

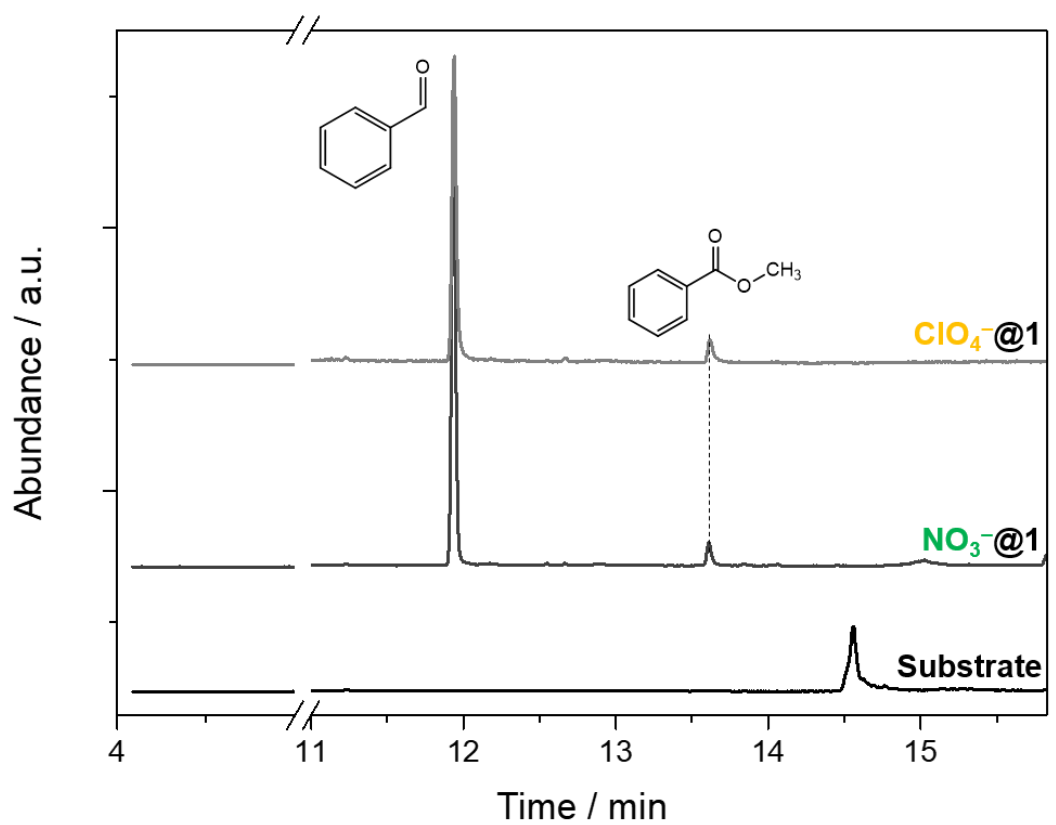

Figure S16. Chromatograms obtained for the pure substrate in toluene and for the aliquots of reactions performed using $\mathrm{NO}_{3}{ }^{-} @ 1$ and $\mathrm{ClO}_{4}{ }^{-} @ \mathbf{1}$ in toluene for $48 \mathrm{~h}$. Benzaldehyde (11.94 $\mathrm{min})$ and methyl benzoate (13.62 $\mathrm{min})$ were identified as products by GC-MS. 


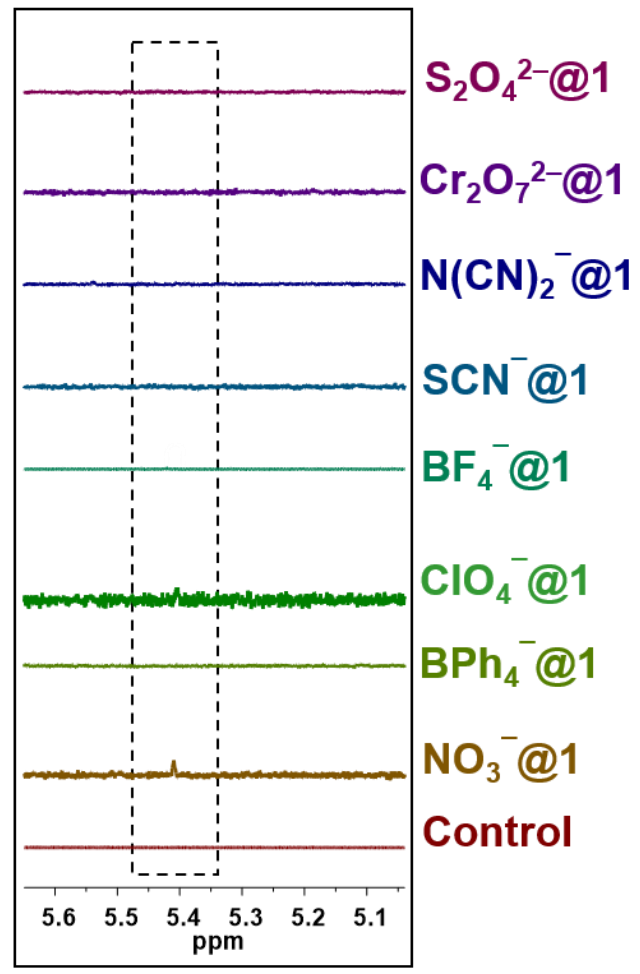

Figure S17. Zoom-in of the ${ }^{1} \mathrm{H}$ NMR spectra in the region between 5.0 and $5.6 \mathrm{ppm}$ showing the peak related to the $\mathrm{CH}$ proton in ketone product (benzoin methyl ether) at $5.4 \mathrm{ppm}$.

\subsection{Volumes of anions used in this study}

Table S1. Molecular weight and solid-state volumes of selected anions. The values of volume were estimated by differential void analysis using crystal structures previously published and deposited in the CCDC data base. The structure codes are shown in Table S2

\begin{tabular}{|c|c|c|c|c|c|c|c|c|}
\hline Formula & $\mathrm{SCN}^{-}$ & $\mathrm{NO}_{3}^{-}$ & $\mathrm{BF}_{4}^{-}$ & $\mathrm{ClO}_{4}^{-}$ & {$\left[\mathrm{N}(\mathrm{CN})_{2}\right]^{-}$} & $\mathrm{S}_{2} \mathrm{O}_{4}{ }^{2-}$ & $\mathrm{Cr}_{2} \mathrm{O}_{7}^{2-}$ & $\mathrm{BPh}_{4}^{-}$ \\
\hline z & -1 & -1 & -1 & -1 & -1 & -2 & -2 & -1 \\
\hline $\mathrm{M}_{\mathrm{w}}\left[\mathrm{g} \mathrm{\textrm {mol } ^ { - 1 }}\right]$ & 58.08 & 62.01 & 86.81 & 99.45 & 66.04 & 128.13 & 215.99 & 319.23 \\
\hline $\mathrm{V}\left[\AA^{3}\right]^{*}$ & 53 & 13 & 46 & 56 & 66 & 32 & 102 & 487 \\
\hline Color change & brown & - & - & - & brown & - & - & - \\
\hline
\end{tabular}


Table S2. Deposition number of the structures used to estimate the volume of the anions in the solid state

\begin{tabular}{ccccc}
\hline Anion & \multicolumn{5}{c}{ Deposited Number in CCDC } \\
\cline { 1 - 1 } $\mathrm{SCN}^{-}$ & 1100186 & 162628 & 174128 & - \\
$\mathrm{NO}_{3}{ }^{-}$ & 162694 & 850661 & 821880 & - \\
$\mathrm{BF}_{4}{ }^{-}$ & 203553 & 619597 & 1564412 & - \\
$\mathrm{ClO}_{4}{ }^{-}$ & 228856 & 231922 & 150006 & - \\
{$\left[\mathrm{N}(\mathrm{CN})_{2}\right]^{-\#}$} & 174338 & 152531 & 275277 & 1529277 \\
$\mathrm{~S}_{2} \mathrm{O}_{4}{ }^{2-}{ }^{-}$ & 282559 & 1445112 & - & - \\
$\mathrm{Cr}_{2} \mathrm{O}_{7}{ }^{2-}$ & 170750 & 1130576 & 164033 & - \\
$\mathrm{BPh}_{4}^{-}$ & 244166 & 851098 & 822194 & - \\
\hline
\end{tabular}

*The mean of the anion volumes in this case was made using only two structures, due to the scarcity of structure examples containing the anion dithionite. ${ }^{\#}$ The mean of the anion volumes in this case was made using four structures, since the volumes found were more disparate.

\subsection{Aerobic oxidation of DPME using 1 in the presence of different concentrations of $\mathrm{ClO}_{4}^{-}$}

The reactions were performed as above with 1, except that different amounts of ( $n$ $\left.\mathrm{Bu}_{4} \mathrm{~N}\right) \mathrm{ClO}_{4}(0.03,0.06,0.12$ and $0.24 \mathrm{mmol})$ were added to the vial containing 1 in toluene, followed by the addition of DPME. Aliquots of the reaction were taken after 4, 8, 24, 28, 32 and $48 \mathrm{~h}$, were added to $\mathrm{CDCl}_{3}(1 \mathrm{~mL})$, filtered and examined by ${ }^{1} \mathrm{H} \mathrm{NMR}$ spectroscopy. The kinetics were monitored by means of the benzaldehyde/substrate ratio using the integration of the ${ }^{1} \mathrm{H}$ NMR resonance peaks, considering that peaks observed at approximately $\delta 4.94 \mathrm{ppm}$ in ${ }^{1} \mathrm{H}$ NMR spectra are related to $\mathrm{C}-\mathrm{H}$ proton of substrate and the peaks at approximately $\delta 10.08 \mathrm{ppm}$ are related to $\mathrm{CHO}$ proton from the product benzaldehyde.

\subsection{Reaction performed with DPME in the presence of $\mathrm{NBu}_{4} \mathrm{ClO}_{4}$}

In a $20 \mathrm{~mL}$ glass capped vial, $1 \mathrm{~mL}$ of toluene was added to $20.5 \mathrm{mg}(0.06 \mathrm{mmol})$ of ( $n$ $\left.\mathrm{Bu}_{4} \mathrm{~N}\right) \mathrm{ClO}_{4}$ and $34 \mathrm{mg}(0.15 \mathrm{mmol})$ of DPME. The capped vial was heated at $100{ }^{\circ} \mathrm{C}$ with constant stirring. Aliquots of the reaction were taken after 4, 8, 24, 28, 32 and 48 hours, 
were added to $\mathrm{CDCl}_{3}(1 \mathrm{~mL})$, filtered and examined by ${ }^{1} \mathrm{H}$ NMR spectroscopy (Figure S18).

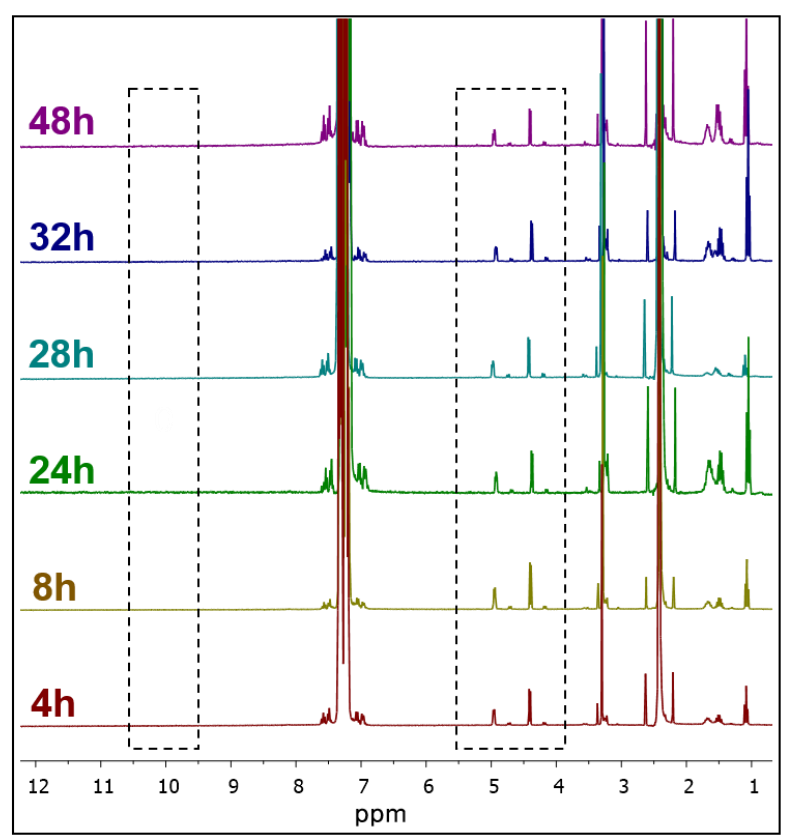

Figure S18. ${ }^{1} \mathrm{H}$ NMR spectra recorded in $\mathrm{CDCl}_{3}$ for the aliquots of the reaction performed using $\mathrm{NBu}_{4} \mathrm{ClO}_{4}$ in toluene in the absence of $\mathbf{1}$. Aliquots were taken at 4, 8, 24, 28, 32 and $48 \mathrm{~h}$ of reaction. The area highlighted by the dotted lines on the right displays the substrate peaks, while those on the left show regions where benzaldehyde product peaks would appear. 


\section{Characterization of $\mathrm{ClO}_{4}^{-} @ 1$ after catalysis}

\subsection{FT-IR}

FT-IR was used as a probe to confirm the retention of $\mathrm{ClO}_{4}^{-} @ \mathbf{1}$ structure. The spectrum of $\mathrm{ClO}_{4}{ }^{-} @ 1$ after the first reaction showed a slight shift of one of the $\mathrm{C}=\mathrm{O}$ bands when compared to the MOF before the catalytic tests (Figure S19 A and B). After the second cycle (reuse), the spectrum showed a broad band related to $\mathrm{O}-\mathrm{H}$ stretching modes centered at $3341 \mathrm{~cm}^{-1}$, and a greater shift of the $\mathrm{C}=\mathrm{O}$ band from $1581 \mathrm{~cm}^{-1}$ for $\mathrm{ClO}_{4}^{-} @ \mathbf{1}$ before catalysis (exchanged with toluene) to $1550 \mathrm{~cm}^{-1}$ for the reused material (Figure S19 C). These evidences could explain the loss of catalytic activity for $\mathrm{ClO}_{4}^{-} @ 1$ after the first cycle. This behavior is presumably due to the fact that water molecules can compete with the substrate for the single open metal sites in the copper(II) paddlewheel decreasing the kinetics of the reaction.

To prove the role of water in the deactivation of the catalyst, we immersed $\mathrm{ClO}_{4}{ }^{-}$ @1 in water for one minute and collected the FT-IR spectrum of this sample (Figure S19 D), which corroborated all the observations made in the spectrum of $\mathrm{ClO}_{4}{ }^{-} @ \mathbf{1}$ after reuse and also evidenced the vanishing of the $\mathrm{Cl}-\mathrm{O}$ stretches bands related to $\mathrm{ClO}_{4}^{-}$in the sample (1074 and $617 \mathrm{~cm}^{-1}$ ). It suggests that water molecules in the medium lead to the formation of hydroxide ions, which coordinate strongly to the copper sites evicting the $\mathrm{ClO}_{4}{ }^{-}$anions from the pores and assuring the charge balance. Hydroxide ions are stronger nucleophiles when compared to water, justifying its irreversible poisoning behavior, preventing the catalyst to be reused. This water-assisted ion-exchange was observed in a very low extension for the material during catalysis though, probably due to the use of toluene in the catalytic reaction and relatively low concentration of water in the medium. 


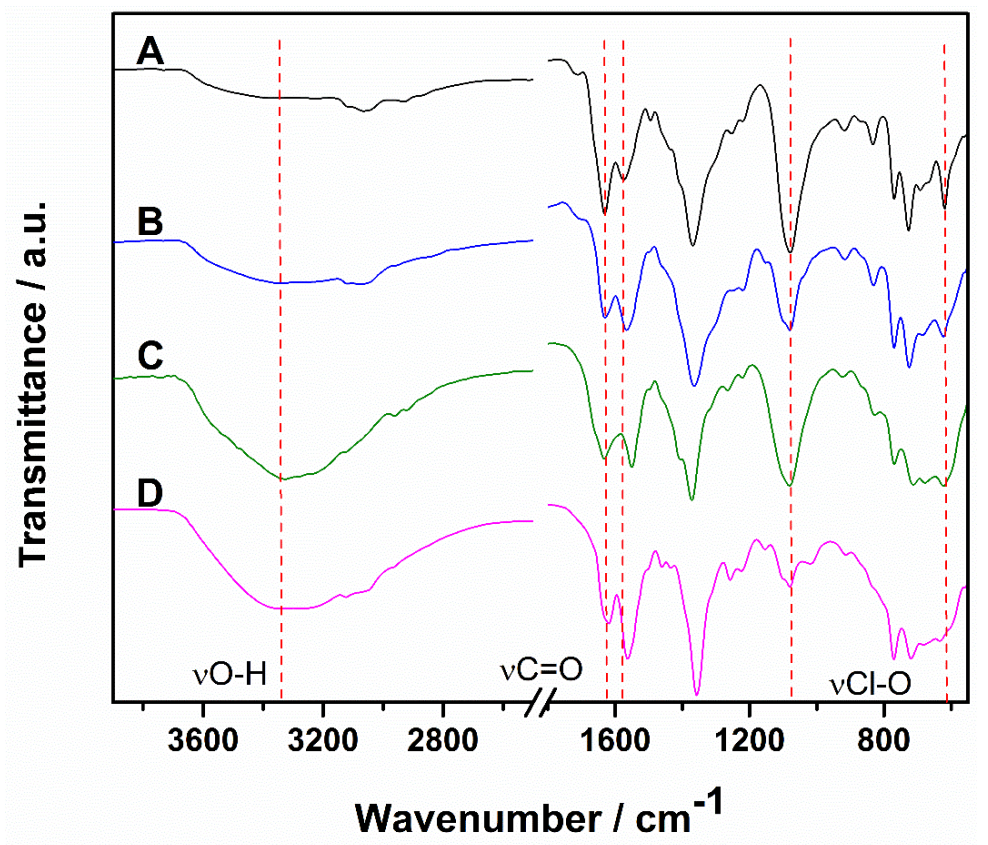

Figure S19. FT-IR spectra of A) $\mathrm{ClO}_{4}{ }^{-} @ 1$ before use in catalysis; $\left.\mathrm{B}\right) \mathrm{ClO}_{4}{ }^{-} @ 1$ after the first use in catalysis; C) $\mathrm{ClO}_{4}^{-} @ \mathbf{1}$ after first reuse; D) $\mathrm{ClO}_{4}^{-} @ \mathbf{1}$ immersed in water for one minute.

\subsection{PXRD}

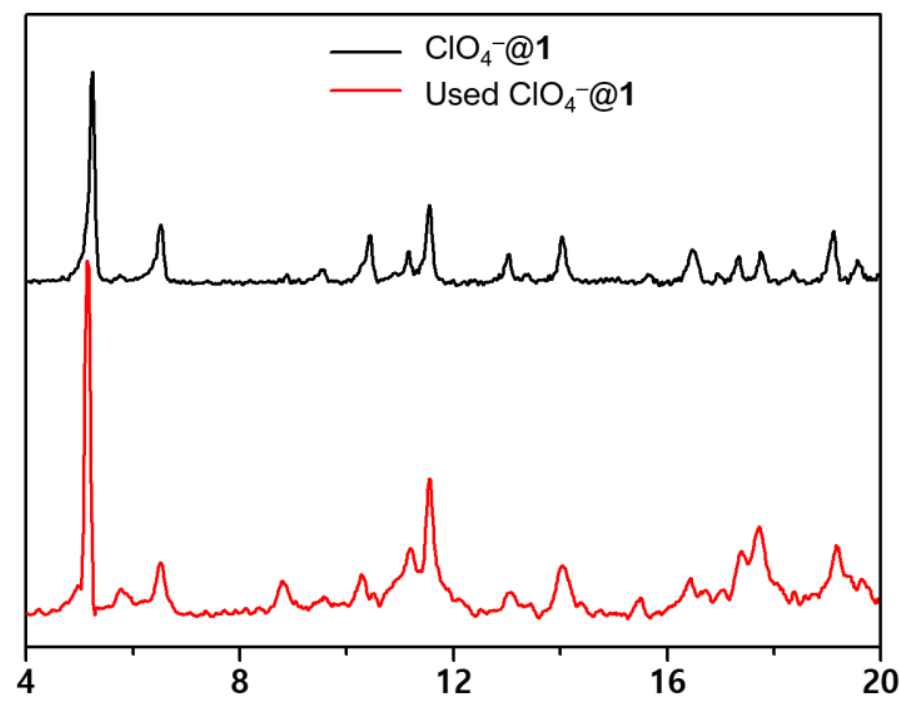

$2 \theta$

Figure S20. PXRD patterns of $\mathrm{ClO}_{4}^{-} @ \mathbf{1}$ before and the after catalytic experiment in toluene. 


\section{Reuse of $\mathrm{ClO}_{4}^{-} @ 1$}

After the first use of $\mathrm{ClO}_{4}^{-} @ \mathbf{1}$ as a catalyst for the aerobic oxidation of DPME, the solid was centrifuged and the resultant solution was separated. The recovered solid was then reused under the same conditions as described above. ${ }^{1} \mathrm{H}$ NMR spectra collected after 48 h of reaction when $\mathrm{ClO}_{4}{ }^{-} @ \mathbf{1}$ was used for the first and second times are shown in Figure S21.

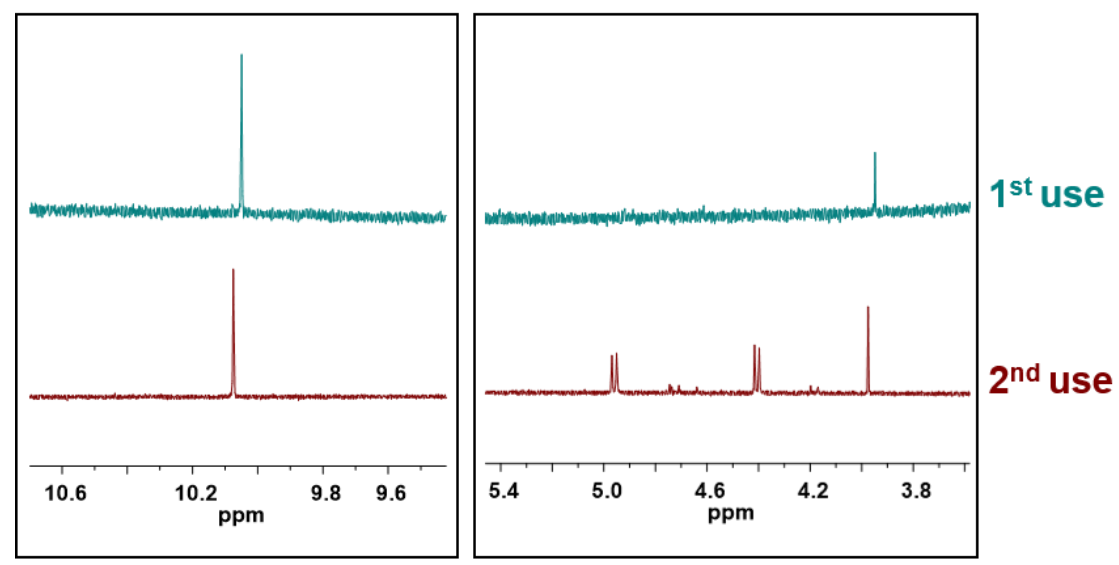

Figure S21. ${ }^{1} \mathrm{H}$ NMR spectra recorded in $\mathrm{CDCl}_{3}$ for the aliquots first and second uses of $\mathrm{ClO}_{4}^{-} @ 1$ as a catalyst for the aerobic oxidation of DPME.

\section{Reuse of the solution after aerobic oxidation of DPME using $\mathrm{ClO}_{4}^{-} @ 1$}

After the first use of $\mathrm{ClO}_{4}^{-} @ \mathbf{1}$ as a catalyst for the aerobic oxidation of DPME, the solid was centrifuged and the resultant solution was separated. A new loading of the substrate (34 mg, $0.15 \mathrm{mmol}$ ) was added to this solution and the mixture heated for $48 \mathrm{~h}$ at $100{ }^{\circ} \mathrm{C}$ under constant stirring in a $20 \mathrm{~mL}$ glass capped vial. One aliquot was taken as the new amount of substrate was loaded $(0 \mathrm{~h})$ and the other after $48 \mathrm{~h}$, added to $\mathrm{CDCl}_{3}(1 \mathrm{~mL})$, filtered and examined by ${ }^{1} \mathrm{H}$ NMR spectroscopy (Figure S22). 


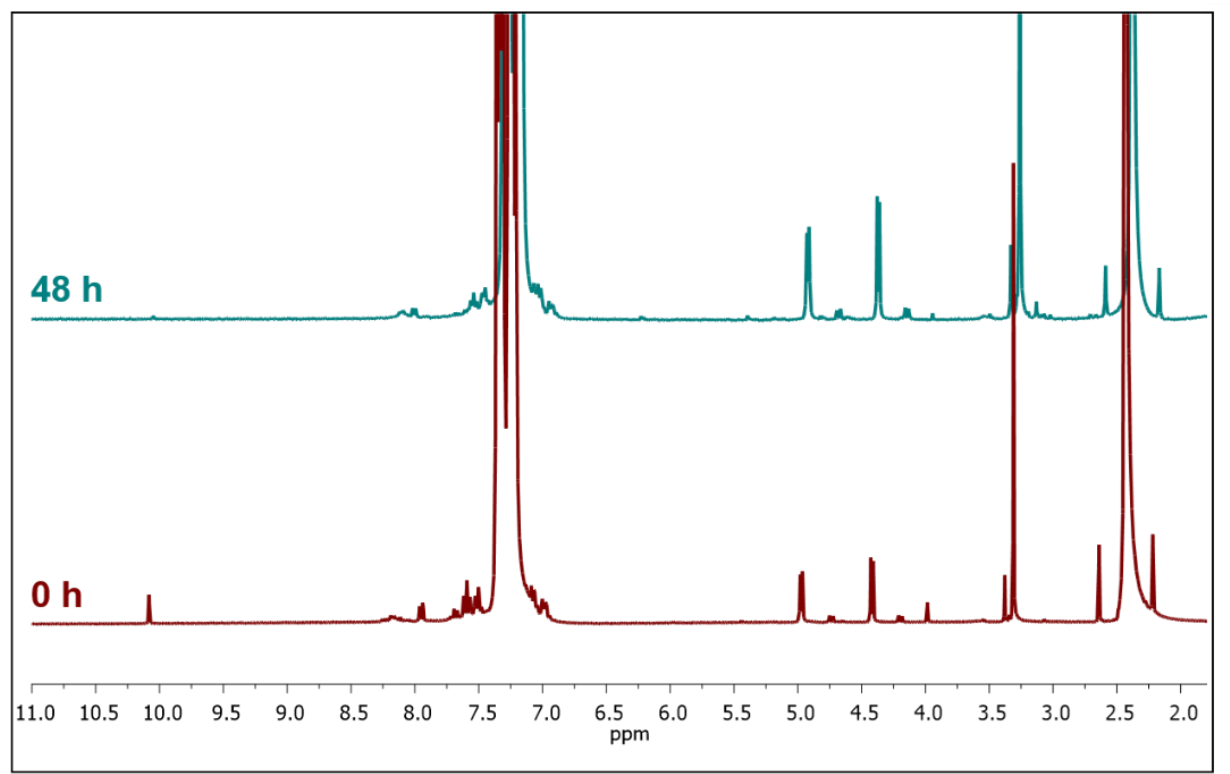

Figure S22. ${ }^{1} \mathrm{H}$ NMR spectra recorded in $\mathrm{CDCl}_{3}$ for the aliquots of the reuse of the solution after the first use of $\mathrm{ClO}_{4}^{-} @ 1$ as a catalyst for the aerobic oxidation of DPME. One aliquot was taken of the medium as the new amount of substrate was loaded $(0 \mathrm{~h}$ spectra) and the other aliquot was taken after $48 \mathrm{~h}$ of heating. The disappearance of the peak related to benzaldehyde (initially present as a product of the first aerobic oxidation of the substrate carried out using $\mathrm{ClO}_{4}^{-} @ 1$ 1) likely arises from over-oxidation to benzoic acid after the additional $48 \mathrm{~h}$ of heating at $100^{\circ} \mathrm{C}$ under air.

\section{Aerobic oxidation of DPME using $\mathrm{ClO}_{4}^{-} @ 1$ in the presence of TEMPO $(2,2,6,6-$ tetramethylpiperidine-1-oxyl) or 4-acetamido-TEMPO}

The reactions were performed as previously mentioned with $\mathrm{ClO}_{4}{ }^{-} @ 1$, except that TEMPO (4.7 mg, $0.03 \mathrm{mmol})$ or 4-acetamido-TEMPO (6.4 mg, $0.03 \mathrm{mmol})$ were also added to the reaction medium. Aliquots of the reactions were taken after 4, 8, 24, 28, 32 and $48 \mathrm{~h}$, were added to $\mathrm{CDCl}_{3}(1 \mathrm{~mL})$, filtered and examined by ${ }^{1} \mathrm{H}$ NMR spectroscopy. The kinetics were monitored by means of the benzaldehyde/substrate ratio using the integration of the $1 \mathrm{H}$ NMR resonances peaks, considering that peaks observed at approximately $\delta 4.94 \mathrm{ppm}$ in ${ }^{1} \mathrm{H}$ NMR spectra are related to $\mathrm{C}-\mathrm{H}$ proton of substrate and the peaks at approximately $\delta 10.08 \mathrm{ppm}$ are related to $\mathrm{CHO}$ proton from the product benzaldehyde. 


\section{Aerobic oxidation of DPME using NOTT-102}

The reactions were performed as previously mentioned with NOTT-102 $(19.1 \mathrm{mg}, 0.03$ mmol). Aliquots of the reactions were taken after 4, 8, 24, 28, 32 and $48 \mathrm{~h}$, were added to $\mathrm{CDCl}_{3}$ (1 mL), filtered and examined by ${ }^{1} \mathrm{H}$ NMR spectroscopy. The kinetics were monitored by means of the benzaldehyde/substrate ratio using the integration of the ${ }^{1} \mathrm{H}$ NMR resonances peaks, considering that peaks observed at approximately $\delta 4.94 \mathrm{ppm}$ in ${ }^{1} \mathrm{H}$ NMR spectra are related to $\mathrm{C}-\mathrm{H}$ proton of substrate and the peaks at approximately $\delta 10.08$ ppm are related to $\mathrm{CHO}$ proton from the product benzaldehyde.

\section{References}

(1) Lin, X.; Telepeni, I.; Blake, A. J.; Dailly, A.; Brown, C. M.; Simmons, J. M.; Zoppi, M.; Walker, G. S.; Thomas, K. M.; Mays, T. J.; Hubberstey, P.; Champness, N. R.; Schröder, M. High Capacity Hydrogen Adsorption in $\mathrm{Cu}(\mathrm{II})$ Tetracarboxylate Framework Materials: The Role of Pore Size, Ligand Functionalization, and Exposed Metal Sites. J. Am. Chem. Soc. 2009, 131 (6), 2159-2171. https://doi.org/10.1021/ja806624j.

(2) Hanson, S. K.; Baker, R. T.; Gordon, J. C.; Scott, B. L.; Thorn, D. L. Aerobic Oxidation of Lignin Models Using a Base Metal Vanadium Catalyst. Inorg. Chem. 2010, 49 (12), 5611-5618. https://doi.org/10.1021/ic100528n. 